\title{
Identification of markers of prostate cancer progression using candidate gene expression
}

\author{
SET Larkin*,1,7, S Holmes ${ }^{2}$, IA Cree ${ }^{3}$, T Walker ${ }^{3}$, V Basketter ${ }^{2}$, B Bickers', S Harris ${ }^{4}$, SD Garbis ${ }^{5,6}$, \\ PA Townsend ${ }^{*, 6,9}$ and C Aukim-Hastie ${ }^{1,8,9}$
}

'School of Pharmacy and Biomedical Sciences, University of Portsmouth, St Michaels Building, White Swan Road, Portsmouth, POI 2DT, UK: ${ }^{2}$ Department of Urology, Queen Alexandra Hospital, Portsmouth, PO6 3LY, UK; ${ }^{3}$ Translational Oncology Research Centre, Queen Alexandra Hospital, Portsmouth, PO6 3LY, UK: ${ }^{4}$ Public Health Sciences and Medical Statistics, University of Southampton, Southampton, UK; ${ }^{5}$ Biomedical Research

Foundation, Academy of Athens, Athens, Greece; ${ }^{6}$ Cancer Sciences Unit, Faculty of Medicine, University of Southampton, Southampton, UK

BACKGROUND: Metastatic prostate cancer (PCa) has no curative treatment options. Some forms of PCa are indolent and slow growing, while others metastasise quickly and may prove fatal within a very short time. The basis of this variable prognosis is poorly understood, despite considerable research. The aim of this study was to identify markers associated with the progression of PCa. METHODS: Artificial neuronal network analysis combined with data from literature and previous work produced a panel of putative PCa progression markers, which were used in a transcriptomic analysis of 29 radical prostatectomy samples and correlated with clinical outcome.

RESULTS: Statistical analysis yielded seven putative markers of PCa progression, ANPEP, ABLI, PSCA, EFNA I, HSPB I, INMT and TRIPI 3. Two data transformation methods were utilised with only markers that were significant in both selected for further analysis. ANPEP and EFNA I were significantly correlated with Gleason score. Models of progression co-utilising markers ANPEP and ABLI or ANPEP and PSCA had the ability to correctly predict indolent or aggressive disease, based on Gleason score, in $89.7 \%$ and $86.2 \%$ of cases, respectively. Another model of TRIPI 3 expression in combination with preoperative PSA level and Gleason score was able to correctly predict recurrence in $85.7 \%$ of cases.

CONCLUSION: This proof of principle study demonstrates a novel association of carcinogenic and tumourigenic gene expression with PCa stage and prognosis.

British Journal of Cancer (2012) 106, I57-165. doi:I0.1038/bjc.2011.490 www.bjcancer.com

Published online 10 November 2011

(C) 2012 Cancer Research UK

Keywords: Taqman; qPCR; prostate cancer; ANPEP; ABLI; PSCA; TRIPI 3

Prostate cancer $(\mathrm{PCa})$ is the most common male cancer in the United Kingdom and accounts for $12 \%$ of male cancer deaths, making it the second most common cause of male cancer death (CRUK, 2010). At present, the use of markers such as PSA to indicate the presence of prostatic disease are severely flawed and lead to unnecessary biopsy procedures, putting patients at risk of infection and haemorrhage. In addition, many patients with high PSA levels are PCa negative on investigation of the biopsy and, conversely, PCa can occur without a rise in PSA and tends to be a more aggressive form of the disease. Once a diagnosis of $\mathrm{PCa}$ is

\footnotetext{
*Correspondence: Dr SET Larkin; E-mail: S.Larkin@soton.ac.uk or Professor PA Townsend; E-mail: P.A.Townsend@soton.ac.uk

${ }^{7}$ Current address: Cancer Sciences Unit, Faculty of Medicine, University of Southampton, Duthie Building (MP 808), Southampton General Hospital, Tremona Road, Southampton SOI6 6YD, UK.

${ }^{8}$ Current address: Division of Health and Social Care, Faculty of Health and Medical Sciences, Duke of Kent Building, University of Surrey, Guildford GU2 7TE, UK.

9 Joint senior authors.

Received 12 July 2011; revised 29 September 2011; accepted 14 October 201 I; published online 10 November 2011
}

confirmed, staging from a biopsy specimen is extremely problematic because of the multifocal nature of the disease. Inappropriate staging of the tumour may lead to radical procedures such as prostate excision, which can lead to a risk of: incontinence (35\%), impotence $(58 \%)$, infection, thrombosis or haemorrhage (Wilt et $a l, 2008)$. Approximately $20 \%$ of radical prostatectomy patients will recur indicating that a conservative treatment strategy might have been more appropriate if one could identify those patients at low risk of recurrence (Bill-Axelson et al, 2008). Equally, metastatic $\mathrm{PCa}$ has a variable prognosis with some patients suffering from a more indolent form of the disease with no significant impact on their quality of life or lifespan for at least 15 years. This has led to the use of monitoring strategies where patients' PSA levels are monitored and biopsies taken if required. If there is evidence of $\mathrm{PCa}$ growth, radical prostatectomy or other treatments may be suggested (NICE, 2008). However, some patients suffer from a more aggressive form of $\mathrm{PCa}$, with a median time to clinically apparent metastasis of 2 years (Siddiqui et al, 2004). These patients quickly develop local effects of urinary incontinence and pelvic pain and often present with late stage prostate disease, with local spread and occult metastasis, a stage at which there are no curative treatment options. Currently, there is no definitive method to differentiate indolent from aggressive 
disease. The use of watchful waiting strategies are more acceptable to patients but in some may lead to the unchecked growth and spread of a prostate tumour, especially of those more aggressive tumours, which do not express PSA.

Quantitative real-time PCR (qPCR) has become a useful tool for validation and reduction of data produced from microarray studies (VanGuilder et al, 2008). Many PCa biomarker studies employ microarrays to identify profiles of the disease and its progression (Chetcuti et al, 2001; Ding et al, 2006). However, these studies produce huge volumes of data that are difficult to analyse and resolve further. Chetcuti et al (2001) studied 588 genes in benign and malignant prostate tissue. They identified 87 genes that showed differential expression between the two tissue types. Ding et al (2006) studied 12000 genes in normal and metastatic PCa cell lines. Both studies then utilised GPCR to further analyse the data produced by microarray analysis.

Standard qPCR is labour intensive, and therefore validation of $>10-20$ genes is rare. Taqman arrays present a mediumthroughput method for qPCR, enabling the analysis of up to 383 genes per assay card (Abruzzo et al, 2005).

The aim of our current study was to identify putative PCa progression markers by using a panel of 91 genes and assessing expression levels in PCa tissue.

\section{MATERIALS AND METHODS}

\section{Tissue specimens}

Ethical approval was obtained and informed written consent was given by each patient included in this study. All PCa patients were from the Portsmouth region and were included if they had undergone radical prostatectomy between 2003 and 2006 and had no other cancers. Radical prostatectomy specimens were formalin fixed, paraffin embedded and stored within the Department of Pathology at Queen Alexandra Hospital following routine clinical analysis. A total of 29 tissue samples were successfully analysed: 18 Gleason score $\geqslant 7$ and 11 Gleason score $<7,20$ without recurrence and 9 with recurrence. Specimen collection was based on the principles of scientific sampling as described by Garfield (2000) and other references therein. Although Gleason scoring is flawed as an indicator of progression, it still remains one of the best indicators of lymph node involvement, treatment failure and death from PCa (NICE, 2008) and as such is routinely recorded in clinic notes making this a well-documented endpoint to assess. Markers found to be differentially expressed between Gleason score, groupings may be indicative of a more aggressive phenotype so could be assessed in longer term survival studies.

\section{Identification of putative biomarkers}

Taqman arrays were designed (genes included on the array are detailed in Supplementary Information, Supplementary Table 1) and ordered from Applied Biosystems (Carlsbad, CA, USA). The arrays were made up of a panel of putative PCa markers primarily derived from an analysis of published microarray data using artificial neuronal networks (ANNs) (Narayanan and Keedwell, 2006). Although the analysis by Narayanan and Keedwell (2006) focussed on diagnostic markers, it has been observed frequently that some diagnostic markers are altered during disease progression also. Therefore, this study was utilised to provide an unbiased panel for Taqman analysis. As ANNs are mathematical models that use complex statistical modelling to learn from and reduce large data sets, such as microarray data, the genes selected were more likely to contain markers of interest (Abbod et al, 2007). Narayanan and Keedwell (2006) utilised Affymetrix (Santa Clara, CA, USA) data from 102 samples (52 PCa cases and 50 normal) spanning 12533 genes (Welsh et al, 2001) to assess the use of 'perceptrons' to identify the most important carcinogenesis genes within an extensive data set. A perceptron is an iterative algorithm that can inspect the effect of each gene on the output classification. Narayanan and Keedwell (2006) used two methods to reduce the genes to a core set of PCa-associated genes: a cross-validation method involving three rounds of iterative training with a crossvalidation step after each iteration (102 samples divided into four groups); and an iteration only method, which just involved three rounds of iterative training, no cross-validation (102 samples divided into three groups). The methods employed were similar to those used previously to study melanoma and childhood medulloblastoma (Narayanan et al, 2004a, b). The cross-validation method yielded 52 genes and the iteration only method yielded 44 genes, 21 of which were common to the cross-validation method. This study utilised the genes identified by the iteration only method to include in the panel of markers for qPCR analysis as this incorporated all of the samples for maximum knowledge discovery (Narayanan and Keedwell, 2006). Additional markers were included following a review of current literature to identify further putative PCa progression markers. Pubmed was used to search for $\mathrm{PCa}$ prognosis markers and progression markers. The most promising markers, based upon prostate biology and discussions with urologists and original authors, were included on the array (e.g., prostate stem cell antigen (PSCA)). In addition, markers identified from our previous work were also included, such as ANXA2 and CD9 (Hastie et al, 2005).

To provide information on inter- and intra-assay variation, reference genes included were included on each Taqman array: $18 S$, TBP (TATA box-binding protein), HPRT1 (hypoxanthine phosphoribosyltransferase 1), $P B G D$ (porphobilinogen deaminase) and SDHA (succinate dehydrogenase complex, subunit A), which all showed little variation of expression in prostate and PCa tissues (Aerts et al, 2004; Ohl et al, 2005; Schmidt et al, 2006). PBGD in particular was chosen for normalisation as studies found it to show little variation between PCa tissue of different stage and grade.

\section{Identification and extraction of cancerous tissue}

Tumour tissue was identified by a histopathologist and, to avoid inconsistency, the same histopathologist worked on this project throughout. Haematoxylin and eosin (HE) labelled slides were used to identify regions of the highest grade of $\mathrm{PCa}$ and these regions were marked. The HE slide was then used to guide sampling of the tissue of interest. Where possible, duplicate $0.6 \mathrm{~mm}$ punches were taken using a manual tissue microarray platform (Beecher Instruments, Mitogen, UK). A total of 41 samples were included at this stage.

\section{RNA extraction and two-step qPCR}

RNA was extracted and reverse transcription (RT) performed as detailed by Glaysher et al (2009). Nucleic acid quantification was carried out using the Nanodrop 1000 spectrophotometer according to the instruction manual (Thermo Scientific, Waltham, MA, USA) and the concentrations and purity ratios were recorded. Newly prepared cDNA was subjected to an assessment of quality before large-scale qPCR analysis. PBGD (reference gene) was amplified by qPCR (using the iCycler, Bio-Rad, Hemel Hempstead, UK) in triplicate for each sample and also once for each RT-negative control. Additionally, several no template controls and a positive control in triplicate were included. These 'sighting shot' experiments were performed as detailed by Glaysher et al (2009). The experimental qPCR cycling parameters were; 1 cycle of $50{ }^{\circ} \mathrm{C}$ for $120 \mathrm{~s}$ and $95^{\circ} \mathrm{C}$ for $600 \mathrm{~s}$, then 50 cycles of $95^{\circ} \mathrm{C}$ for $15 \mathrm{~s}$ and $60{ }^{\circ} \mathrm{C}$ for $60 \mathrm{~s}$. A $C_{\mathrm{T}}$ (cycle threshold) of $<40$ was classed as showing good quality cDNA.

The cDNA was prepared and loaded, and the Taqman arrays sealed as described by Glaysher et al (2009) and qPCR performed using the following cycling parameters; heating to $50{ }^{\circ} \mathrm{C}$ for $120 \mathrm{~s}$, 
further heating to $94.5^{\circ} \mathrm{C}$ for $600 \mathrm{~s}$ and then 40 cycles of $97^{\circ} \mathrm{C}$ for $30 \mathrm{~s}$ and $59.7^{\circ} \mathrm{C}$ for $60 \mathrm{~s}$. At the start and end of the trial, a standard curve plate of different dilutions of a pooled cDNA reference sample was performed to determine the efficiency of the assay. Additionally, the same pooled cDNA reference sample was used to perform a triplicate repeat at the start and end of the trial to assess intra- and inter-plate variability. Triplicate data could not be obtained for each sample because of insufficient sample quantity.

\section{Analysis of Taqman array data}

Statistical analysis was performed using SPSS (version 12; IBM, Portsmouth, UK) on samples that showed a $C_{\mathrm{T}}$ of $<35$ for both $18 S$ and $P B G D$. Taqman array data were converted to normalised expression ratios using two methods; the first method was the Applied Biosystems recommended method $\left(2^{-\Delta \Delta \mathrm{C}_{\mathrm{T}}}\right)$ and the second was a method that allows for variation of amplification efficiency (Pfaffl method). Both methods were used to corroborate any findings by two independent analyses. First, the $2^{-\Delta \Delta \mathrm{C}_{\mathrm{T}}}$ method (Bio-Rad, 2006) was used followed by normalisation to PBGD and Ln (natural log) transformation. A Student's $t$-test was then performed to check for significant differences between the two groups. Second, the Pfaffl method was used (see equation in Supplementary Information, Supplementary Table 2), which takes into account the amplification efficiencies of the genes and normalises to a reference gene (PBGD) (Bio-Rad, 2006). This data conversion was also followed by Ln transformation and Student's $t$-test analysis. For both $t$-tests, genes showing differential expression between the indolent and aggressive groups $(P<0.05)$ were considered for further analysis. Genes found to be significantly different were then assessed for correlations before logistic regression to build a model of PCa progression. Correlating variables can confound models as it is difficult to ascertain, which variable makes the greater contribution (Kinnear and Gray, 2007). Logistic regression enables the calculation of the natural log (Ln) of the odds of having a more aggressive/indolent disease. From this, the Ln (odds) can be used as a predictor of indolent/ aggressive disease. An ROC (receiver operator characteristic) curve was drawn from these values to assess the ability of the model to predict PCa progression and to identify an appropriate cut-off point to distinguish between the two groups.

\section{RESULTS}

\section{RNA and cDNA quantification and quality}

Quantification (absorbance at $260 \mathrm{~nm}$ ), purity (260/280 and $260 / 230 \mathrm{~nm}$ ) and integrity (sighting shot experiment) for each sample are presented in the Supplementary Information (Supplementary Table 3). RNA purity is poorer in those samples with lower quantity, but once reverse transcribed to cDNA, the purity of the samples was improved. Triplicate $P B G D$ expression was then used as a measure of cDNA quality. A $P B G D C_{\mathrm{T}}<40$ was taken as an indication of adequate quality cDNA. If no amplification was detectable within 40 cycles, it was assumed that there was insufficient starting material.

Following these initial RNA and cDNA analyses, samples were taken forward to be used in the large scale Taqman array study. As a $C_{\mathrm{T}}$ of $<35$ is traditionally thought of as optimal, samples that had a $C_{\mathrm{T}}$ of $>35$ were loaded onto the Taqman array at $600 \mathrm{ng} \mu \mathrm{l}^{-1}$ rather than at $300 \mathrm{ng}^{-1}$ to increase the starting material present. Variation of cDNA starting quantity did not pose a problem as quantification was relative to the amplification of $P B G D$ from the same sample.

\section{Intra- and inter-assay variation}

Amplification of cDNA from each sample was performed without replication because of low RNA yield. Therefore, to assess intra- and inter-assay variation, a pooled sample (a mixture of equal volumes of all the samples) was amplified in triplicate at the beginning and end of this research trial. The initial amplification graph of the pooled sample was used to set the threshold fluorescence, above which each amplicon is classed as having 'come up' (visible fluorescent signal). The threshold was set at 0.5 so that it was above background noise but still within the exponential phase of amplification (ABI, 2006). A standard curve plate was also included in the trial and consisted of varying concentrations $\left(75,150,300\right.$ and $\left.600 \mathrm{ng} \mu \mathrm{l}^{-1}\right)$ of the pooled sample and from this the amplification efficiency and $R^{2}$ values were calculated.

An optimised qPCR assay should have an efficiency of between $90 \%$ and $105 \%$ and an $R^{2}$ of $>0.98$ (Bio-Rad, 2006). Of the reference genes included; $18 \mathrm{~S}$ was within the correct range for amplification efficiency, SDHA and TBP were within the correct range for $R^{2}$ and HPRT1 and $P B G D$ fell outside those ranges for both values $\left(R^{2}=0.235\right.$ and 0.802 , respectively, amplification efficiencies $=363.9$ and 59.7, respectively). A further measure of qPCR accuracy and reproducibility is the variation between replicates and between different Taqman arrays. Coefficient of variation $(\mathrm{CV})$ was calculated from replicate values within the replicate plates and mean values between replicate plates (Kinnear and Gray, 2007). In order to calculate $\mathrm{CVs}, C_{\mathrm{T}}$ values were converted to actual quantities using the absolute quantification method (see equation in Supplementary Information, Supplementary Table 4). This method uses standard curves of known starting material concentrations to calculate quantity of cDNA. Absolute quantification was used in this calculation to remove the need to normalise to $P B G D$ enabling the assessment of $P B G D$ reproducibility concurrently. Intra-assay variation was lowest for $S D H A$ and $18 S$, but inter assay variation was lowest for $P B G D$.

\section{Quantitative real-time PCR}

Initial analysis of qPCR data for reference gene expression showed that only 29 of the initial 41 samples had amplifiable cDNA. Student's $t$-tests were carried out on these 29 samples in both the $2^{\Delta \Delta \mathrm{C}_{\mathrm{T}}}$ and Pfaffl (see equation in Supplementary Information, Supplementary Table 2) normalised data sets and identified 10 genes that were significantly different between groups divided according to Gleason score (Table 1). Preoperative PSA was also assessed as a predictor of Gleason score. ANPEP and EFNA1 were significantly different in both data sets with $99 \%$ confidence, the remaining genes were significant to $95 \%$ confidence. All genes showed a significant reduction in expression in aggressive disease compared with indolent disease.

A more accurate method of studying progression of disease is to compare gene expression of patients who have suffered recurrent disease, biochemically or with evidence of distant metastasis, with those who have not. Levels of PSA should be undetectable within 4 weeks of radical prostatectomy (Stephenson et al, 2006), so biochemical recurrence was determined by a rising PSA following radical prostatectomy. Evidence of distant metastasis was taken from bone scans. Disease recurrence in all cases was advised by our collaborating clinicians. In this study, between 2 and 5 years clinical follow-up was available for patients. This data analysis identified three genes, ANPEP, INMT and TRIP13; the expression of which was significantly different between patients using both data conversion methods (Table 2). INMT and ANPEP expression showed a significant decrease (to $99 \%$ and $95 \%$ confidence, respectively) in recurrent disease while TRIP13 expression was significantly increased (to $95 \%$ confidence) in recurrent disease. Preoperative PSA and Gleason score were also assessed as predictors of recurrence. Gleason score was subjected to a MannWhitney $U$-test rather than a Gleason as the data are ordinal.

Genes found to be differentially expressed were then subject to correlation analysis before logistic regression. Correlation analysis 
Table I Genes found to be significantly differentially expressed between Gleason groups $<7$ and $\geqslant 7 \mathrm{PCa}$

\begin{tabular}{|c|c|c|c|c|}
\hline \multirow[b]{2}{*}{ Gene } & \multirow[b]{2}{*}{$\begin{array}{l}2^{-\Delta \Delta C_{T}} \\
\text { (P-value) }\end{array}$} & \multicolumn{2}{|c|}{ Mean } & \multirow[b]{2}{*}{$\begin{array}{c}\text { Fold } \\
\text { change }\end{array}$} \\
\hline & & $\begin{array}{c}\text { Gleason } \\
\text { group }<7\end{array}$ & $\begin{array}{l}\text { Gleason } \\
\text { group } \geqslant 7\end{array}$ & \\
\hline INMT & 0.015 & -0.29 & -1.42 & 4.90 \\
\hline PSCA & 0.024 & -0.75 & -2.78 & 3.71 \\
\hline ITGB4 & 0.021 & 0.47 & -0.90 & 2.91 \\
\hline NELL2 & 0.018 & -0.96 & -2.29 & 2.39 \\
\hline ANPEP & 0.005 & 1.36 & -1.16 & 2.17 \\
\hline EFNAI & 0.006 & 2.29 & 1.18 & 1.94 \\
\hline$A B L I$ & 0.037 & 2.05 & 1.12 & 1.83 \\
\hline HSPB I & 0.025 & 2.18 & 1.45 & 1.50 \\
\hline GPM6A & 0.015 & -2.54 & -3.54 & 1.39 \\
\hline \multirow[t]{2}{*}{ CD9 } & 0.028 & 3.47 & 2.87 & 1.21 \\
\hline & $\begin{array}{c}\text { Pfaffl } \\
(P \text {-value })\end{array}$ & $\begin{array}{c}\text { Gleason } \\
\text { group }<7\end{array}$ & $\begin{array}{l}\text { Gleason } \\
\text { group } \geqslant 7\end{array}$ & $\begin{array}{l}\text { Fold } \\
\text { change }\end{array}$ \\
\hline PSCA & 0.044 & 0.01 & -2.08 & 209.00 \\
\hline ANPEP & 0.011 & 0.19 & -2.30 & 13.11 \\
\hline GPM $6 A$ & 0.043 & 1.70 & 0.27 & 6.30 \\
\hline$A B L I$ & 0.028 & 0.99 & -0.30 & 3.30 \\
\hline CD9 & 0.018 & 0.69 & -0.28 & 3.46 \\
\hline INMT & 0.031 & 0.57 & -1.09 & 2.91 \\
\hline EFNAI & 0.004 & 0.55 & -0.93 & 2.69 \\
\hline HSPBI & 0.037 & 0.68 & -0.47 & 2.45 \\
\hline ITGB4 & 0.017 & 0.88 & -0.61 & 2.44 \\
\hline NELL2 & 0.015 & 0.84 & -0.59 & 2.42 \\
\hline PSA & 0.346 & 6.53 & 8.06 & 1.23 \\
\hline
\end{tabular}

Abbreviations: $\mathrm{PCa}=$ prostate cancer; $\mathrm{PSA}=$ prostate specific antigen. $\mathrm{qPCR}$ data were converted using the $2^{-\Delta \Delta \mathrm{C}_{\mathrm{T}}}$ and Pfaff conversion methods and then statistically analysed using Student's t-tests. Genes are ordered by descending fold change Preoperative PSA data have been included for comparison.

Table 2 Genes found to be differentially expressed between patients with and without recurrent disease

\begin{tabular}{|c|c|c|c|c|}
\hline \multirow[b]{2}{*}{ Gene } & \multirow[b]{2}{*}{$\begin{array}{c}2^{-\Delta \Delta C_{T}} \\
(P \text {-value })\end{array}$} & \multicolumn{2}{|c|}{ Mean } & \multirow[b]{2}{*}{$\begin{array}{c}\text { Fold } \\
\text { change }\end{array}$} \\
\hline & & $\begin{array}{c}\text { No } \\
\text { recurrence }\end{array}$ & Recurrence & \\
\hline \multirow{4}{*}{$\begin{array}{l}\text { ANPEP } \\
\text { INMT } \\
\text { TRIPI3 }\end{array}$} & 0.041 & 0.48 & -1.70 & 4.58 \\
\hline & 0.010 & -0.56 & -1.95 & 3.48 \\
\hline & 0.031 & -3.11 & -1.70 & 1.83 \\
\hline & $\begin{array}{c}\text { Pfaffl } \\
(P \text {-value })\end{array}$ & $\begin{array}{c}\text { No } \\
\text { recurrence }\end{array}$ & Recurrence & $\begin{array}{l}\text { Fold } \\
\text { change }\end{array}$ \\
\hline INMT & 0.006 & 0.14 & -1.80 & 13.64 \\
\hline ANPEP & 0.03 & $-0.7 \mid$ & -2.80 & 3.97 \\
\hline TRIPI3 & 0.03 & -16.92 & 7.73 & 3.19 \\
\hline PSA & 0.195 & 6.81 & 9.07 & 1.33 \\
\hline Gleason score & $0.051 *$ & 6.55 & 7.10 & - \\
\hline
\end{tabular}

Abbreviation: PSA = prostate specific antigen. * $P$-value calculated by Mann - Whitney $U$-test. QPCR data were converted using the $2^{-\Delta \Delta C_{T}}$ and Pfaffl conversion methods and then statistically analysed using Student's $t$-tests. Genes are ordered by descending fold change. Preoperative PSA and Gleason score data have been included for comparison

was used to identify genes with correlating expression levels as these could not be included in the same logistic regression models. In addition, correlation analysis was performed for gene expression and PSA level before radical prostatectomy and, in the recurrence analysis, Gleason score. Briefly, most genes correlated with each other in the Pfaffl data set, with the exception of EFNA1,
$A B L 1, G P M 6 A$ and PSCA. Further, INMT correlated with PSA. The $2^{-\Delta \Delta \mathrm{C}_{\mathrm{T}}}$ data set showed fewer correlating genes, so most genes could be included in multiple logistic regression analyses. However, INMT and HSPB1 were found to correlate with PSA and $A N P E P$ to correlate with Gleason score. Correlation analysis of the genes from the recurrence groupings found that expression levels do correlate across all three genes in both data sets, except INMT and TRIP13 in the $2^{-\Delta \Delta \mathrm{C}_{\mathrm{T}}}$ data set.

Logistic regression was initially carried out for each gene individually and with PSA and Gleason score (where applicable). The genes with the highest 'percentage predicted correctly' were combined to find the best model from the data sets. Table 3 shows the logistic regression data for both data sets divided by Gleason score and recurrence. Analysis of the $2^{-\Delta \Delta \mathrm{C}_{\mathrm{T}}}$ data set identified EFNA1 and $A B L 1$ as good single markers to predict Gleason grouping, a combined model utilising $A N P E P$ and $A B L 1$ as predictors of Gleason grouping and INMT as a predictor of recurrence. Analysis of INMT and TRIP13 expression combined as a model of recurrence did not significantly improve the prediction capability over using INMT alone. However, combining TRIP13 with PSA or Gleason score greatly improved the prediction capability of the model. Studying the Pfaffl data set found HSPB1 to be a good single marker and ANPEP and PSCA or CD9 and PSA combined to predict Gleason grouping, whereas $A N P E P$ alone or a combined model of TRIP13, PSA and Gleason score were identified as the most accurate predictors of recurrence.

Receiver operator characteristic curves were drawn for the single and combination markers listed in Table 3. Receiver operator characteristic curves are a further manner of investigating significance and are also used to identify appropriate levels for assigning subjects to one group or another. ROC curves are presented in Figure 1. A good ROC curve is indicated by an 'area under the curve' (AUC) of close to one. The coordinates used to produce the ROC curve were used to identify the appropriate gene expression value, which would be used to assign subjects into a particular disease grouping. The cut point is identified as the point at which the sensitivity and specificity are highest and patients with a value below the cut point are more likely to have aggressive disease. The values and the corresponding sensitivity and specificity are detailed in Table 4.

An ideal ROC curve should have high sensitivity and specificity (or low 1-specificity), which means a low probability of false negatives and a low probability of false positives (Kinnear and Gray, 2007). The best ROC curves were produced by the two models using combined expression of two genes, $A N P E P$ and $A B L 1$ $(\mathrm{AUC}=0.889)$ in the $2^{-\Delta \Delta \mathrm{C}_{\mathrm{T}}}$ data set and ANPEP and PSCA (AUC $=0.869)$ in the Pfaffl data set, for prediction of Gleason score grouping. A combined model using TRIP13, PSA and Gleason score in the Pfaffl data set was also very good at predicting recurrence $(\mathrm{AUC}=0.888)$.

Within the $2^{-\Delta \Delta C_{\mathrm{T}}}$ data set, the best predictive model was a combined gene expression model of ANPEP and ABL1. This model could correctly assign $89.7 \%$ of patients to indolent or aggressive disease groups based on Gleason score. Using a cutoff of -0.16 , patients with a higher score could be identified as indolent with $82 \%$ sensitivity and $94 \%$ specificity. Patients with lower expression of $A N P E P$ and $A B L 1$ could be at risk of potentially aggressive disease. Similarly, the best predictive model within the Pfaffl data set was a combined model of ANPEP and PSCA, which could correctly assign $86.2 \%$ of patients to indolent and aggressive groupings based on Gleason score. A cutoff of -0.25 could predict indolent or aggressive disease groupings with $82 \%$ sensitivity and $94 \%$ specificity. Again, a score below this cutoff would be indicative of a more aggressive phenotype. Finally, a good predictive model was also found from the Pfaffl data set, a combined model of TRIP13 with pre-operative PSA and Gleason score of radical was able to correctly assign recurrence in $85.7 \%$ of patients. A cutoff of 0.14 could predict recurrence with $87.5 \%$ 
Table 3 Logistic regression analysis of the best progression models

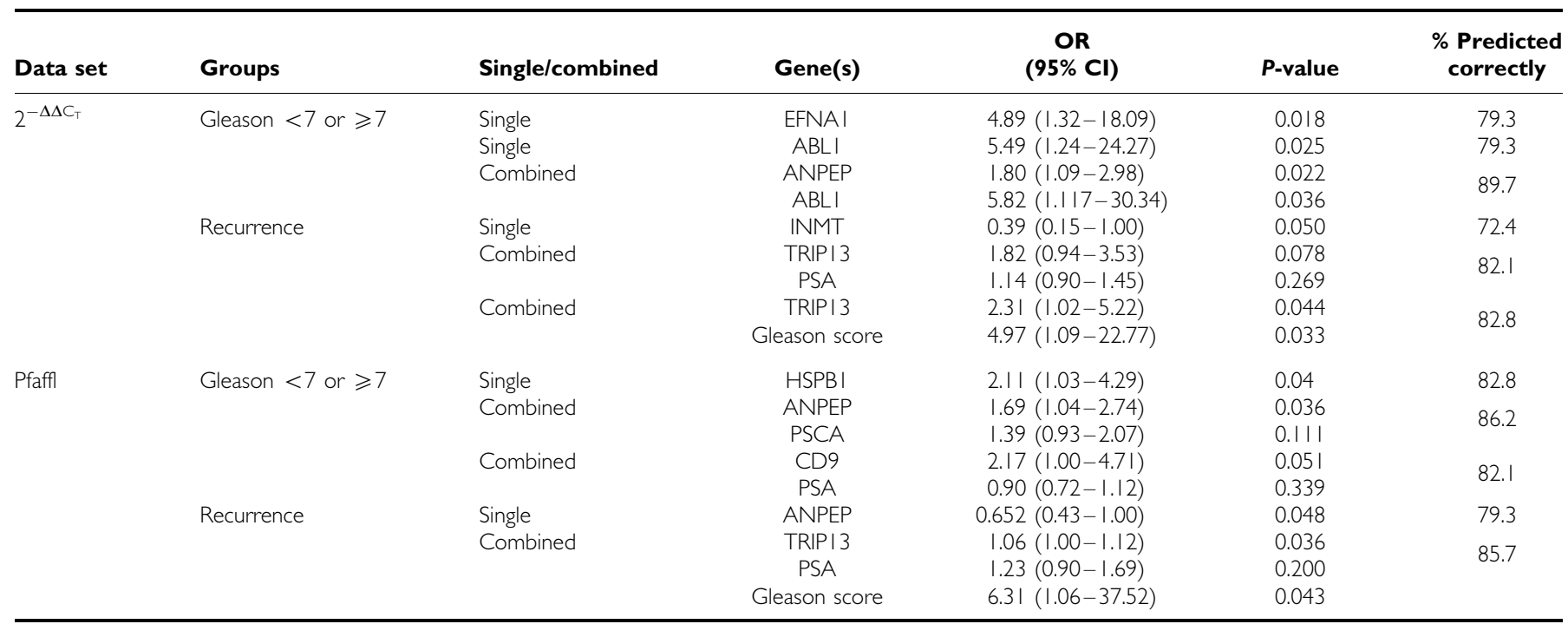

Abbreviations: $\mathrm{Cl}=$ confidence interval; $\mathrm{OR}=$ odds ratio; PSCA = prostate stem cell antigen; PSA = prostate specific antigen. Single and combined marker models were assessed using logistic regression for both $2^{-\Delta \Delta C_{T}}$ and Pfaffl data in Gleason and recurrence divided groupings. OR are given (with $95 \%$ Cls) of an individual having a higher chance of indolent disease with a lower gene expression level.

sensitivity and $90 \%$ specificity. A score above this cutoff would be indicative of a high chance of recurrence.

Single gene models identified EFNA1, ABL1 and HSPB1 as predictors of Gleason score grouping, and INMT and ANPEP as predictors of recurrence grouping. Both EFNA1 and ABL1 (using the $2^{-\Delta \Delta \mathrm{C}_{\mathrm{T}}}$ data set) had the ability to predict $79.3 \%$ of patients as having indolent or aggressive disease. EFNA1, with a cut point of -0.40 , could predict aggressivity of disease with $82 \%$ sensitivity and $83 \%$ specificity and $A B L 1$, with a cut point of -0.30 , could predict aggressivity of disease with $73 \%$ sensitivity and $79 \%$ specificity. INMT, identified using the $2^{-\Delta \Delta \mathrm{C}_{\mathrm{T}}}$ data set, could predict recurrence of disease in $72.4 \%$ of patients and had a sensitivity and specificity of $89 \%$ and $65 \%$, respectively, with a cut point of -1.16 . Using the Pfaffl data set, HSPB1 could accurately assign patients into aggressive grouping by Gleason score in $82.8 \%$ of cases and using a cut point of -0.54 had a sensitivity and specificity of $64 \%$ and $94 \%$, respectively. ANPEP could assign patients into recurrence grouping in $79.3 \%$ of cases and with a cut point of 0.31 could predict recurrence with $78 \%$ sensitivity and $70 \%$ specificity. As with the combined gene models, a score lower than the cut point is indicative of aggressive disease.

\section{DISCUSSION}

This study highlights that, because of the complexity of cancer, many genes and proteins are likely to be differentially regulated, and underpins the difficulty of biomarker discovery. Many biomarkers (both diagnostic and prognostic) are identified by researchers but few result in clinically viable tests. Biomarkers that are not significantly better than current testing methods, such as PSA, are unlikely to be embraced by clinicians and, so far, none of the biomarkers discovered have the sensitivity or specificity to replace PSA. Owing to the complexity of $\mathrm{PCa}$ (and cancer in general), it is perhaps naive to imagine that a single gene or protein marker will indeed be able to fulfil all of the 'ideal biomarker' criteria. This is a 'proof of concept' study that highlights the utility of an informed approach when searching for disease biomarkers. Garfield (2000) mentions that sample number is generally limited by resources available for sample collection and sample analysis. For a 'proof of concept' study lower sample numbers are generally acceptable, but findings would need to be validated in a larger set of specimens. If validated, the use of these markers could enable clinicians to distinguish between indolent and aggressive forms of the disease and offer informed clinical management options.

Taqman arrays customised for potential PCa progression markers were used to study gene expression in a pilot series of 29 patients. By a variety of data analysis methods, 10 genes were identified, 6 of which could be accurately used to predict PCa progression (defined by Gleason or recurrence) in up to $89.7 \%$ of cases. The six genes that were best used to model PCa progression included: ANPEP, EFNA1, ABL1, INMT, HSPB1 and PSCA. TRIP13 was also an accurate predictor of recurrence when used in conjunction with preoperative PSA and Gleason score.

Aminopeptidase $\mathrm{N}$, or CD13 (ANPEP) is a zinc-dependent matrix metallopeptidase that is membrane bound and thought to have an important role in angiogenesis (Shim et al, 2008). Studies of mRNA and protein expression of ANPEP in malignancy are conflicting, with some suggesting an overexpression as an indicator of cancer presence (Razvi et al, 2007) and a role for ANPEP in invasion and metastasis (Ishii et al, 2001) whereas others propose that reduced expression is associated with cancer (Bogenrieder et al, 1997; Wiese et al, 2007). A study by Bhagwat et al (2001) examined the effect of tumour microenvironment-like conditions on primary endothelial cells and ANPEP production. They found ANPEP to be upregulated in response to hypoxia and increased concentrations of growth factors at both the mRNA and protein level. There are some papers that have studied ANPEP expression in PCa cell lines and suggest that ANPEP shows reduced expression in cancer cells (Dall'Era et al, 2007) and that there is a significant reduction in expression between LNCaP and PC3 (which have a more aggressive phenotype) cells (Dozmorov et al, 2009). However, there are no studies into ANPEP expression in varying Gleason score PCa tissue so the association of ANPEP with Gleason score is novel. It is tempting to suggest that, as angiogenesis is a feature of early-to-mid stage tumourigenesis, perhaps proangiogenic molecules are downregulated in established poorly differentiated tumours such as Gleason score 7-10 PCa.

The tyrosine kinase, c-Abl, is a protein belonging to the Src family of non-receptor tyrosine kinases that has been implicated in the intrinsic apoptosis pathway, triggered in response to DNA 


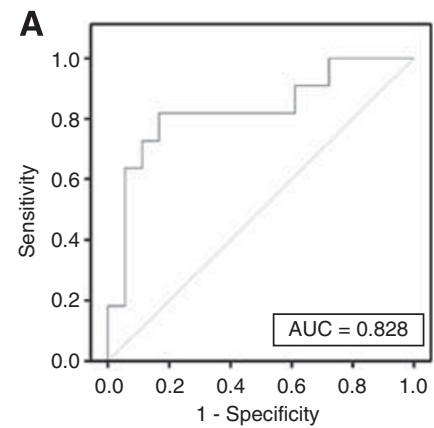

(i) EFNA1

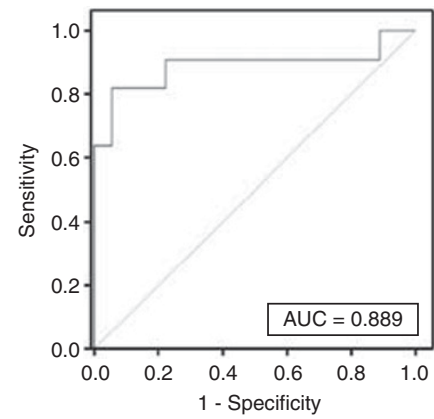

(iii) ANPEP and ABL1

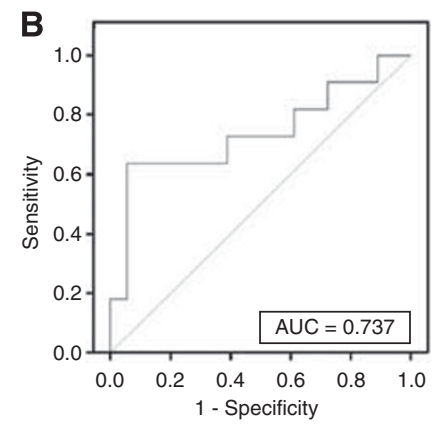

(i) HSPB1

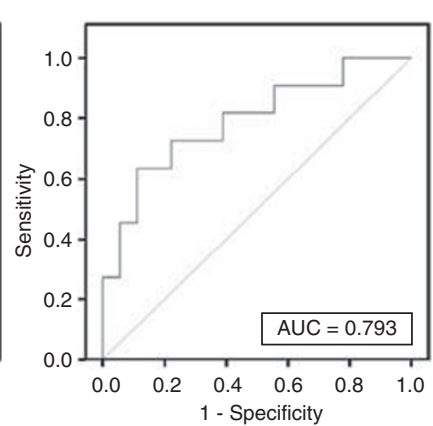

(ii) ABL1

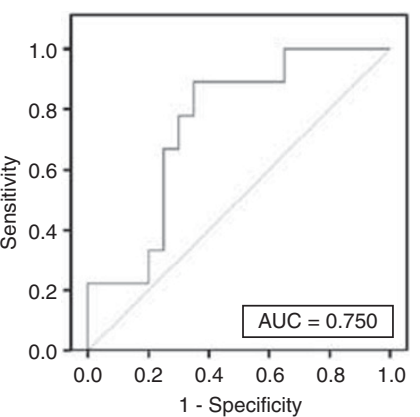

(iv) INMT

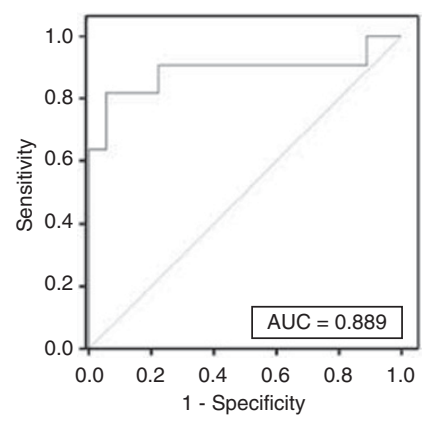

(ii) ANPEP and PSCA

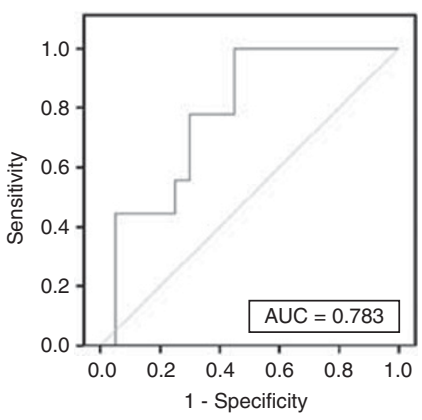

(iii) ANPEP

Figure I Receiver operator characteristic curves of gene expression as a predictor of PCa progression based on Gleason score and recurrence using the $(\mathbf{A}) 2^{-\Delta \Delta C_{T}}$ data set and the (B) Pfaffl data set. The AUC of each curve is included in the bottom right hand corner of each chart. An ideal AUC should be close to I.

damage (Yamaguchi et al, 2010). c-Abl is encoded by the $A B L 1$ gene whose translocation to the $B C R$ gene results in the $\mathrm{BCR}-\mathrm{Abl}$ fusion protein, known to be involved in the development of some leukaemias (Sirvent et al, 2008). In cancers that do not have the $B C R-A b l$ translocation, $A B L 1$ seems to show reduced expression. A study of bladder transitional cell carcinoma found a significant

reduction in $A B L 1$ expression in cancerous compared with normal tissue (Amira et al, 2004). In PCa progression, we found $A B L 1$ to be downregulated. During carcinogenesis, one of the proposed hallmarks is that a cancer cell must evade apoptosis (Hanahan and Weinberg, 2000). By being able to downregulate proapoptotic molecules, such as c-abl, cells can evade apoptosis and continue to proliferate.

Prostate stem cell antigen is a cell surface antigen belonging to the Ly6 family of glycosyl phosphatidylinositol anchored proteins. The Ly6 family consist of at least nine proteins thought to be involved in haematopoietic stem cell development and lymphocyte activation. PSCA shows $30 \%$ homology to stem cell antigen 2, which has a putative role in prostate development (Moore et al, 2008). Generally, PSCA over-expression has been shown to be associated with PCa presence and progression (Han et al, 2004; Zhigang and Wenlv, 2004; Lam et al, 2005). However, a study by (Schmidt et al, 2006) found no relationship between PSCA RNA or protein expression and PCa presence or increasing Gleason score. Another study utilising qPCR to study common PCa markers found a reduction of PSCA RNA expression in malignant compared with benign tissue (Fuessel et al, 2003). Further, Moore et al (2008) performed a study of tumour development and progression in TRAMP (transgenic adenocarcinoma of the mouse prostate) mice with wild-type PSCA and heterozygous and homozygous knockout for PSCA. They found at autopsy that a much higher percentage of heterozygous and homozygous PSCA knockout mice had metastatic disease. They postulated that PSCA may have a 'context-dependent function' with a dual role in $\mathrm{PCa}$ progression. Our results support their finding and suggest a role for PSCA in aggressive PCa. Perhaps PSCA under-expression is associated with the metastatic progression of $\mathrm{PCa}$ whereas the over-expression is a feature of the early stages of cellular carcinogenesis.

A variety of developmental processes are implicated in cancer development and progression. Therefore, it is perhaps unsurprising that Ephs and ephrins, which have a role in developmental pathways, are found to be deregulated in carcinogenesis (Fox et al, 2006). EFNA1 (ephrin A1) is a ligand that is generally associated with the eph A2 transmembrane receptor and has a putative inhibitory role in angiogenesis and cell growth (Nakamura et al, 2005). Over-expression of eph A2 has been shown to be a significant prognostic indicator (Wu et al, 2004; Han et al, 2005; Nakamura et al, 2005). However, Nakamura et al (2005) report a negative correlation of eph a2 and EFNA1 expression, with EFNA1 involved in eph a2 degradation and negatively affecting tumour growth (Abraham et al, 2006) and VEGF-associated angiogenesis (Ojima et al, 2006). Therefore, a decreased level of EFNA1 would be expected to promote cell growth and angiogenesis associated with higher grade PCa. This is in contrast to the findings of ANPEP, a pro-angiogenic molecule. However, both showed decreased expression in this study suggesting that they may be involved in different angiogenic pathways.

Heat shock proteins are expressed ubiquitously in all cells and tissues (Kurahashi et al, 2007). HSPB1 (HSP27) is a heat shock protein thought to be involved in cell survival and has been linked to stress-induced apoptosis and invasion in colorectal cell lines (Garrido et al, 1997). Our findings of a decrease in HSPB1 mRNA expression associated with a more aggressive $\mathrm{PCa}$ phenotype is in contrast to studies of protein level expression of HSPB1 in PCa (Cornford et al, 2000; Kurahashi et al, 2007) and breast, ovarian and head and neck cancer (O'Callaghan-Sunol et al, 2007). However, a study of oral squamous cell carcinoma found the reverse to be true (Lo Muzio et al, 2006). It has been suggested that HSPB1 has a role in the stress response and apoptosis evasion (Huang et al, 2007). The results of our study could be merely due to the utilisation of a transcriptomic rather than a proteomic approach suggesting regulation of HSPB1 may be post-translational rather than at the level of transcription. Studies into the 
Table 4 ROC curve cut points as determined by logistic regression analysis

\begin{tabular}{|c|c|c|c|c|c|}
\hline Data set & Groupings & Gene(s) & Cut point & Sensitivity & Specificity \\
\hline Pfaffl & $\begin{array}{l}\text { Gleason } \\
\text { Recurrence }\end{array}$ & $\begin{array}{l}\text { HSPBI } \\
\text { ANPEP + PSCA } \\
\text { CD9 + PSA } \\
\text { ANPEP } \\
\text { TRIPI + PSA + Gleason score }\end{array}$ & $\begin{array}{r}-0.535 \\
-0.2453 \\
0.0015 \\
0.3083 \\
0.1390\end{array}$ & $\begin{array}{l}0.636 \\
0.818 \\
0.636 \\
0.778 \\
0.875\end{array}$ & $\begin{array}{l}0.944 \\
0.944 \\
0.941 \\
0.700 \\
0.900\end{array}$ \\
\hline
\end{tabular}

Abbreviations: $\mathrm{PCa}=$ prostate cancer; PSCA = prostate stem cell antigen; ROC = receiver operator characteristic. Sensitivity and specificity values for each ROC curve cut point are also included for each model of PCa progression.

correlation of RNA and protein expression in PCa suggest no significant relationship, or even an inverse relationship, between the two molecular levels (Chen et al, 2002).

Indolethylamine $\mathrm{N}$-methyltransferase (INMT) is a methylation catalyst involved in the methylation of tryptamine during the production of $N \mathrm{~N}$-dimethyltryptamine (Jacob and Presti, 2005). This pathway is normally associated with brain activity and psychosis but some studies have found a link between INMT expression and cancer. Lian et al (2006) studied PTEN activity in endometrial cancer and found deregulated expression of INMT associated with PTEN loss. In another study into non-small cell lung cancer (NSCLC), decreased expression of INMT was associated with cancerous tissue when compared with normal lung (Kopantzev et al, 2008). Similarly, qPCR data from this study found decreased expression of INMT in the more aggressive PCa cases. The implication of the downregulation of INMT in association with the progression of $\mathrm{PCa}$ is unclear.

TRIP13 is a thyroid receptor interacting protein (Lee et al, 1995) whose gene shows copy number changes in $68 \%$ of 19 early stage NSCLC tumour samples (Kang et al, 2008). TRIP13 has also been implicated as a marker of early disease related mortality in multiple myeloma as part of a 70-gene model. Further multivariate analysis identified a subset of 17 genes that had a similar predictive power, but TRIP13 did not feature in this smaller panel (Shaughnessy et al, 2007). TRIP13 has been found to interact with CMT2 (Stelzl et al, 2005), a key player in the mitosis spindle checkpoint, and is required for cell cycle progression (Habu et al, 2002). It is interesting that TRIP13 (by its interaction with CMT2) is implicated in cancer progression as spindle checkpoint defects are known to contribute to loss of chromosome integrity, which can lead to aneuploidy, a common feature of cancer cells (Bharadwaj and Yu, 2004).

The use of multiple biomarkers showed a greater ability to correctly identify aggressive disease than single biomarkers alone and therefore, multivariate analysis may be preferable to univariate analysis. This is unsurprising as cancer is a temporally and spatially complex disease that occurs as a result of several mutations to genes involved in a variety of biochemical pathways. Moreover, carcinogenic mutations may not be identical for each individual. It may be inappropriate to expect a single marker to be able to identify progressive disease with a great deal of accuracy as has been suggested in this study and others (Cheville et al, 2008; Kosari et al, 2008).

Quantitative real-time PCR has become one of the most widely utilised methods of gene expression analysis in disease onset and progression. Many studies have utilised this technique to validate microarray data. Partheen et al (2008) utilised qPCR to validate a panel of seven genes identified via microarray analysis as prognostic factors in ovarian adenocarcinoma. The study yielded four genes as potential biomarkers from a sample of only
19 patients. These data were then verified by looking at protein level expression in a larger cohort. Studies into PCa have also utilised qPCR to study gene expression. Research into a panel of eight putative diagnostic markers identified one gene as a significant predictor of PCa (Rizzi et al, 2008), whereas another study began with a panel of nine PCa markers and identified one as diagnostic, but a further three that were indicative of organconfined disease (Schmidt et al, 2006). By using Taqman arrays to study gene expression, it is possible to study larger panels of putative markers than was possible for these studies.

The design of this study may have resulted in potential sample bias as only radical prostatectomy samples were used. Radical prostatectomy tends only to be performed with organ-confined lower grade disease so there is a bias towards low recurrence risk disease. Perhaps a further study of biopsy specimens would overcome any potential bias. An alternative approach might have been to utilise mass spectrometry methods to identify putative protein markers and then design a Taqman array accordingly, but this would be a more biased approach. Additional characterisation could take place at the protein level by immunohistochemical methods and analysis of serum expression via western blotting or ELISA.

In conclusion, this 'proof of concept' study presents a putative gene panel of PCa progression. In order to verify any signature, a further study on a large 'test sample set' is warranted to investigate disease recurrence or survival and would verify and validate any potential prognostic indicators. Interestingly, these markers were assessed in the mRNA expression data produced by Taylor et al (2010) and ANPEP and TRIP13 found to be significantly differentially expressed in terms of Gleason score and biochemical and metastatic recurrence, respectively (Supplementary Data Table 4). ABL1 was not found to be significant but was approaching significance. Several other genes identified from this study were also verified by Taylor et al (2010) as putative markers of PCa progression so should be considered for further study. Taken together, our new data and that within the literature show significant complementarity and will help further our biomarker targeting for the future.

\section{ACKNOWLEDGEMENTS}

We are grateful to all of the members of the Translational Oncology Research Centre, both old and new, for training and advice, Wessex Medical Research, and all members of the AukimHastie and Townsend laboratories. This study was funded by CanTech Ltd.

Supplementary Information accompanies the paper on British Journal of Cancer website (http://www.nature.com/bjc) 


\section{REFERENCES}

Abbod MF, Catto JW, Linkens DA, Hamdy FC (2007) Application of artificial intelligence to the management of urological cancer. J Urol 178(4 Pt 1): $1150-1156$

ABI (2006) Running TaqMan Low Density Arrays on 7900HT Real-Time PCR Systems. Vol. 2008, Applied-Biosystems: USA

Abraham S, Knapp D, Cheng L, Snyder P, Mittal S, Bangari D, Kinch M, Wu L, Dhariwal J, Mohammed S (2006) Expression of EphA2 and Ephrin A-1 in carcinoma of the urinary bladder. Clin Cancer Res 12(2): $353-360$

Abruzzo LV, Lee KY, Fuller A, Silverman A, Keating MJ, Medeiros LJ, Coombes KR (2005) Validation of oligonucleotide microarray data using microfluidic low-density arrays: a new statistical method to normalize real-time RT-PCR data. Biotechniques 38(5): 785-792

Aerts JL, Gonzales MI, Topalian SL (2004) Selection of appropriate control genes to assess expression of tumor antigens using real-time RT-PCR Biotechniques 36(1): 84-86

Amira N, Cancel-Tassin G, Bernardini S, Cochand-Priollet B, Bittard H, Mangin P, Fournier G, Latil A, Cussenot O (2004) Expression in bladder transitional cell carcinoma by real-time quantitative reverse transcription polymerase chain reaction array of 65 genes at the tumor suppressor locus 9q34.1-2: identification of 5 candidates tumor suppressor genes. Int $J$ Cancer 111(4): 539-542

Bhagwat S, Lahdenranta J, Giordano R, Arap W, Pasqualini R, Shapiro L (2001) CD13/APN is activated by angiogenic signals and is essential for capillary tube formation. Blood 97(3): 652-659

Bharadwaj R, Yu H (2004) The spindle checkpoint, aneuploidy, and cancer. Oncogene 23(11): 2016-2027

Bill-Axelson A, Holmberg L, Filen F, Ruutu M, Garmo H, Busch C, Nordling S, Haggman M, Andersson S, Bratell S (2008) Radical prostatectomy versus watchful waiting in localized prostate cancer: the Scandinavian prostate cancer group-4 randomized trial. J Natl Cancer Inst 100(16): $1144-1154$

Bio-Rad (2006) Real-Time PCR; Applications Guide, 1st edn Bio-Rad Laboratories Inc.: UK

Bogenrieder T, Finstad CL, Freeman RH, Papandreou CN, Scher HI, Albino AP, Reuter VE, Nanus DM (1997) Expression and localization of aminopeptidase $\mathrm{A}$, aminopeptidase $\mathrm{N}$, and dipeptidyl peptidase IV in benign and malignant human prostate tissue. Prostate 33(4): $225-232$

Chen X, Ding Y, Liu CG, Mikhail S, Yang CS (2002) Overexpression of glucose-regulated protein 94 (Grp94) in esophageal adenocarcinomas of a rat surgical model and humans. Carcinogenesis 23(1): 123-130

Chetcuti A, Margan S, Mann S, Russell P, Handelsman D, Rogers J, Dong Q (2001) Identification of differentially expressed genes in organ-confined prostate cancer by gene expression array. Prostate 47(2): $132-140$

Cheville JC, Karnes RJ, Therneau TM, Kosari F, Munz JM, Tillmans L, Basal E, Rangel LJ, Bergstralh E, Kovtun IV, Savci-Heijink CD, Klee EW, Vasmatzis G (2008) Gene panel model predictive of outcome in men at high-risk of systemic progression and death from prostate cancer after radical retropubic prostatectomy. J Clin Oncol 26(24): 3930-3936

Cornford P, Dodson A, Parsons K, Desmond A, Woolfenden A, Fordham M, Neoptolemos J, Ke Y, Foster C (2000) Heat shock protein expression independently predicts clinical outcome in prostate cancer. Cancer Res 60(24): 7099-7105

CRUK (2010) Prostate Cancer Mortality Statistics for the UK. Vol. 2010 CRUK: UK

Dall'Era MA, True LD, Siegel AF, Porter MP, Sherertz TM, Liu AY (2007) Differential expression of $\mathrm{CD} 10$ in prostate cancer and its clinical implication. BMC Urol 7(1): 3

Ding Y, Xu L, Chen S, Jovanovic BD, Helenowski IB, Kelly DL, Catalona WJ, Yang XJ, Pins M, Ananthanarayanan V, Bergan RC (2006) Characterization of a method for profiling gene expression in cells recovered from intact human prostate tissue using RNA linear amplification. Prostate Cancer Prostatic Dis 9(4): 379-391

Dozmorov MG, Hurst RE, Culkin DJ, Kropp BP, Frank MB, Osban J, Penning TM, Lin HK (2009) Unique patterns of molecular profiling between human prostate cancer LNCaP and PC-3 cells. Prostate 69(10): $1077-1090$

Fox BP, Tabone CJ, Kandpal RP (2006) Potential clinical relevance of Eph receptors and ephrin ligands expressed in prostate carcinoma cell lines. Biochem Biophys Res Commun 342(4): 1263-1272

Fuessel S, Sickert D, Meye A, Klenk U, Schmidt U, Schmitz M, Rost AK, Weigle B, Kiessling A, Wirth MP (2003) Multiple tumor marker analyses
(PSA, hK2, PSCA, trp-p8) in primary prostate cancers using quantitative RT-PCR. Int J Oncol 23(1): 221-228

Garfield FM (2000) Quality Assurance Principles for Analytical Laboratories 3rd edn AOAC International: Gaithersburg, MD

Garrido C, Ottavi P, Fromentin A, Hammann A, Arrigo AP, Chauffert B, Mehlen P (1997) HSP27 as a mediator of confluence-dependent resistance to cell death induced by anticancer drugs. Cancer Res 57(13): $2661-2667$

Glaysher S, Yiannakis D, Gabriel FG, Johnson P, Polak ME, Knight LA, Goldthorpe Z, Peregrin K, Gyi M, Modi P, Rahamim J, Smith ME, Amer K, Addis B, Poole M, Narayanan A, Gulliford TJ, Andreotti PE, Cree IA (2009) Resistance gene expression determines the in vitro chemosensitivity of non-small cell lung cancer (NSCLC). BMC Cancer 9: 300

Habu T, Kim SH, Weinstein J, Matsumoto T (2002) Identification of a MAD2-binding protein, CMT2, and its role in mitosis. EMBO J 21(23): $6419-6428$

Han KR, Seligson DB, Liu X, Horvath S, Shintaku PI, Thomas GV, Said JW, Reiter RE (2004) Prostate stem cell antigen expression is associated with gleason score, seminal vesicle invasion and capsular invasion in prostate cancer. J Urol 171(3): 1117-1121

Han L, Dong Z, Qiao Y, Kristensen GB, Holm R, Nesland JM, Suo Z (2005) The clinical significance of EphA2 and Ephrin A-1 in epithelial ovarian carcinomas. Gynecol Oncol 99(2): 278-286

Hanahan D, Weinberg R (2000) The hallmarks of cancer. Cell 100(1): 57-70 Hastie C, Saxton M, Akpan A, Cramer R, Masters JR, Naaby-Hansen S (2005) Combined affinity labelling and mass spectrometry analysis of differential cell surface protein expression in normal and prostate cancer cells. Oncogene 24(38): 5905-5913

Huang L, Min JN, Masters S, Mivechi NF, Moskophidis D (2007) Insights into function and regulation of small heat shock protein 25 (HSPB1) in a mouse model with targeted gene disruption. Genesis 45(8): $487-501$

Ishii K, Usui S, Sugimura Y, Yoshida S, Hioki T, Tatematsu M, Yamamoto $\mathrm{H}$, Hirano K (2001) Aminopeptidase $\mathrm{N}$ regulated by zinc in human prostate participates in tumor cell invasion. Int J Cancer 92(1): 49-54

Jacob MS, Presti DE (2005) Endogenous psychoactive tryptamines reconsidered: an anxiolytic role for dimethyltryptamine. Med Hypotheses 64(5): $930-937$

Kang JU, Koo SH, Kwon KC, Park JW, Kim JM (2008) Gain at chromosomal region $5 \mathrm{p} 15.33$, containing TERT, is the most frequent genetic event in early stages of non-small cell lung cancer. Cancer Genet Cytogenet 182(1): $1-11$

Kinnear PR, Gray CD (2007) SPSS 15 Made Simple. Psychology: Hove

Kopantzev EP, Monastyrskaya GS, Vinogradova TV, Zinovyeva MV Kostina MB, Filyukova OB, Tonevitsky AG, Sukhikh GT, Sverdlov ED (2008) Differences in gene expression levels between early and later stages of human lung development are opposite to those between normal lung tissue and non-small lung cell carcinoma. Lung Cancer 62(1): $23-34$

Kosari F, Munz JM, Savci-Heijink CD, Spiro C, Klee EW, Kube DM, Tillmans L, Slezak J, Karnes RJ, Cheville JC, Vasmatzis G (2008) Identification of prognostic biomarkers for prostate cancer. Clin Cancer Res 14(6): $1734-1743$

Kurahashi T, Miyake H, Hara I, Fujisawa M (2007) Expression of major heat shock proteins in prostate cancer: correlation with clinicopathological outcomes in patients undergoing radical prostatectomy. J Urol 177(2): 757-761

Lam JS, Yamashiro J, Shintaku IP, Vessella RL, Jenkins RB, Horvath S, Said JW, Reiter RE (2005) Prostate stem cell antigen is overexpressed in prostate cancer metastases. Clin Cancer Res 11(7): 2591-2596

Lee JW, Choi HS, Gyuris J, Brent R, Moore DD (1995) Two classes of proteins dependent on either the presence or absence of thyroid hormone for interaction with the thyroid hormone receptor. Mol Endocrinol 9(2): 243

Lian Z, De Luca P, Di Cristofano A (2006) Gene expression analysis reveals a signature of estrogen receptor activation upon loss of Pten in a mouse model of endometrial cancer. $J$ Cell Physiol 208(2): 255-266

Lo Muzio L, Campisi G, Farina A, Rubini C, Ferrari F, Falaschini S, Leonardi R, Carinci F, Stalbano S, De Rosa G (2006) Prognostic value of HSP27 in head and neck squamous cell carcinoma: a retrospective analysis of 57 tumours. Anticancer Res 26(2B): 1343-1349

Moore M, Teitell M, Kim Y, Watabe T, Reiter R, Witte O, Dubey P (2008) Deletion of PSCA increases metastasis of TRAMP-induced 
prostate tumors without altering primary tumor formation. Prostate 68(2): $139-151$

Nakamura R, Kataoka H, Sato N, Kanamori M, Ihara M, Igarashi $\mathrm{H}$, Ravshanov S, Wang YJ, Li ZY, Shimamura T, Kobayashi T, Konno H, Shinmura K, Tanaka M, Sugimura H (2005) EPHA2/EFNA1 expression in human gastric cancer. Cancer Sci 96(1): 42-47

Narayanan A, Keedwell ETT (2006) Perceptrons for analysing prostate cancer gene expression data. unpublished

Narayanan A, Keedwell EC, Gamalielsson J, Tatineni S (2004a) Single-layer artificial neural networks for gene expression analysis. Neurocomputing 61: $217-237$

Narayanan A, Nana E, Keedwell E (2004b) Analyzing gene expression data for childhood medulloblastoma survival with artificial neural networks. Proc 2004 IEEE Symposium Computational Intelligence Bioinform Computational Biol 5: 9-16

NICE (2008) Prostate Cancer: Diagnosis and Treatment Vol. 2010. NICE: $\mathrm{UK}$

O'Callaghan-Sunol C, Gabai VL, Sherman MY (2007) Hsp27 modulates p53 signaling and suppresses cellular senescence. Cancer Res 67(24): $11779-11788$

Ohl F, Jung M, Xu C, Stephan C, Rabien A, Burkhardt M, Nitsche A, Kristiansen G, Loening SA, Radonic A, Jung K (2005) Gene expression studies in prostate cancer tissue: which reference gene should be selected for normalization? J Mol Med 83(12): 1014-1024

Ojima T, Takagi H, Suzuma K, Oh H, Suzuma I, Ohashi H, Watanabe D, Suganami E, Murakami T, Kurimoto M (2006) EphrinA1 inhibits vascular endothelial growth factor-induced intracellular signaling and suppresses retinal neovascularization and blood-retinal barrier breakdown. Am J Pathol 168(1): $331-339$

Partheen K, Levan K, Osterberg L, Claesson I, Fallenius G, Sundfeldt K, Horvath G (2008) Four potential biomarkers as prognostic factors in stage III serous ovarian adenocarcinomas. Int J Cancer 123(9): $2130-2137$

Razvi MH, Peng D, Dar AA, Powell SM, Frierson Jr HF., Moskaluk CA, Washington K, El-Rifai W (2007) Transcriptional oncogenomic hot spots in Barrett's adenocarcinomas: serial analysis of gene expression. Genes Chromosomes Cancer 46(10): 914-928

Rizzi F, Belloni L, Crafa P, Lazzaretti M, Remondini D, Ferretti S, Cortellini P, Corti A, Bettuzzi S (2008) A novel gene signature for molecular diagnosis of human prostate cancer by RT-qPCR. PLoS One 3(10): e3617

Schmidt U, Fuessel S, Koch R, Baretton GB, Lohse A, Tomasetti S, Unversucht S, Froehner M, Wirth MP, Meye A (2006) Quantitative multigene expression profiling of primary prostate cancer. Prostate 66(14): $1521-1534$

Shaughnessy JD, Zhan F, Burington BE, Huang Y, Colla S, Hanamura I, Stewart JP, Kordsmeier B, Randolph C, Williams DR (2007) A validated gene expression model of high-risk multiple myeloma is defined by deregulated expression of genes mapping to chromosome 1 . Blood 109(6): 2276

Shim JS, Park HM, Lee J, Kwon HJ (2008) Global and focused transcriptional profiling of small molecule aminopeptidase $\mathrm{N}$ inhibitor reveals its mechanism of angiogenesis inhibition. Biochem Biophys Res Commun 371(1): $99-103$

Siddiqui E, Mumtaz FH, Gelister J (2004) Understanding prostate cancer. J R Soc Promot Health 124(5): 219-221

Sirvent A, Benistant C, Roche S (2008) Cytoplasmic signalling by the c-Abl tyrosine kinase in normal and cancer cells. Biol Cell 100(11): $617-631$

Stelzl U, Worm U, Lalowski M, Haenig C, Brembeck FH, Goehler H, Stroedicke M, Zenkner M, Schoenherr A, Koeppen S (2005) A human protein-protein interaction network: a resource for annotating the proteome. Cell 122(6): $957-968$

Stephenson AJ, Kattan MW, Eastham JA, Dotan ZA, Bianco FJ, Lilja H, Scardino PT (2006) Defining biochemical recurrence of prostate cancer after radical prostatectomy: a proposal for a standardized definition. J Clin Oncol 24(24): $3973-3978$

Taylor BS, Schultz N, Hieronymus H, Gopalan A, Xiao Y, Carver BS, Arora VK, Kaushik P, Cerami E, Reva B, Antipin Y, Mitsiades N, Landers T, Dolgalev I, Major JE, Wilson M, Socci ND, Lash AE, Heguy A, Eastham JA, Scher HI, Reuter VE, Scardino PT, Sander C, Sawyers CL, Gerald WL (2010) Integrative genomic profiling of human prostate cancer. Cancer Cell 18(1): 11-22

VanGuilder HD, Vrana KE, Freeman WM (2008) Twenty-five years of quantitative PCR for gene expression analysis. Biotechniques 44(5): 619-626

Welsh JB, Sapinoso LM, Su AI, Kern SG, Wang-Rodriguez J, Moskaluk CA, Frierson HF, Hampton GM (2001) Analysis of gene expression identifies candidate markers and pharmacological targets in prostate cancer. Cancer Res 61(16): 5974-5978

Wiese AH, Auer J, Lassmann S, Nahrig J, Rosenberg R, Hofler H, Ruger R, Werner M (2007) Identification of gene signatures for invasive colorectal tumor cells. Cancer Detect Prev 31(4): 282-295

Wilt TJ, MacDonald R, Rutks I, Shamliyan TA, Taylor BC, Kane RL (2008) Systematic review: comparative effectiveness and harms of treatments for clinically localized prostate cancer. Ann Intern Med 148(6): 435-448

Wu D, Suo Z, Kristensen GB, Li S, Troen G, Holm R, Nesland JM (2004) Prognostic value of EphA2 and EphrinA-1 in squamous cell cervical carcinoma. Gynecol Oncol 94(2): 312-319

Yamaguchi T, Miki Y, Yoshida K (2010) The c-Abl tyrosine kinase stabilizes Pitxl in the apoptotic response to DNA damage. Apoptosis 15(8): $927-935$

Zhigang Z, Wenlv S (2004) Prostate stem cell antigen (PSCA) expression in human prostate cancer tissues: implications for prostate carcinogenesis and progression of prostate cancer. Jpn J Clin Oncol 34(7): 414-419

This work is published under the standard license to publish agreement. After 12 months the work will become freely available and the license terms will switch to a Creative Commons Attribution-NonCommercial-Share Alike 3.0 Unported License. 